\title{
Formação de mediadores em museus de ciência: diálogos entre a educação formal e não formal
}

Isabel Gomes ${ }^{1}$

isabelgomes@mast.br

Sibele Cazelli²

sibele@mast.br

\section{Resumo}

O presente trabalho analisa processos de formação de mediadores em dois museus de ciência, considerando as relações entre a educação formal e não formal. Tendo como referência os saberes docentes (TARDIF, 2010), verificou-se que, nesses processos, foram enfatizados saberes disciplinares, da formação profissional e da experiência. Constatou-se também que a formação acadêmica em educação contribui para formação de mediadores, na perspectiva dos próprios. Do ponto de vista da educação não formal, o estabelecimento de parcerias com instituições de formação de professores é uma questão premente para uma melhor qualificação dos profissionais de atuam na área, e esse diálogo pode ser frutífero também em sentido inverso, enriquecendo a formação de docentes da educação básica.

Palavras-chave: educação não formal, educação em museus, museus de ciência, mediação, formação de mediadores.

\section{Abstract}

The present article analyzes mediator training processes that occur in two science museums, taking into account the relations between formal and non formal education. Based on the concept of teacher's knowledge (TARDIF, 2010), it was verified that in those process were emphasized disciplinary, pedagogical and experiential knowledge. It was also discovered that the academic degree in education contributes to training mediators, from their own perspective. From the non-formal education point of view establishing partnership with teacher education institutions is a pressing issue for a better qualification of the professionals working in the area and this dialogue can be useful also in reverse, enriching the training basic education teachers.

Keywords: non-formal education, museum education, science museums, mediation, mediator training

\footnotetext{
1 Mestre em Museologia pela Universidade Federal do Estado do Rio de Janeiro (Uni-Rio) e bolsista do Programa de Capacitação Institucional ( $\mathrm{PCl} / \mathrm{CNPq}$ ) do Museu de Astronomia e Ciências Afins (Mast/MCTI).

2 Doutora em Educação pela Pontifícia Universidade Católica do Rio de Janeiro (PUC-Rio) e pesquisadora do Museu de Astronomia e Ciências Afins (Mast/MCTI).
} 


\section{1 - Introdução}

Os museus de ciência se situam atualmente como importantes elementos na educação em ciências, considerando as diferentes possibilidades proporcionadas pela relação museu-escola, a noção de educação ao longo da vida e as articulações entre ciência, tecnologia e sociedade. Das mudanças mais expressivas ocorridas na história recente dos museus, destaca-se a ampliação de sua função educativa e o fortalecimento de setores específicos para essa finalidade, o que gera uma demanda por profissionais de educação qualificados a atuarem nesses espaços.

Tratar do papel das universidades e escolas, mas também dos museus, na formação de profissionais de educação é importante para o estabelecimento de parcerias que considerem a formação em educação de forma abrangente, levando em conta as articulações entre educação formal e não formal.

Os espaços não formais de educação são relevantes na formação inicial e continuada de professores. A contribuição dos museus para a formação de professores é relacionada tanto ao aprimoramento de práticas pedagógicas que se dão no âmbito escolar, como à utilização dos recursos disponíveis nessas instituições para a sua complementação. De fato, diversos museus desenvolvem ações voltadas para a instrumentalização de professores e licenciandos, no domínio das práticas educativas específicas dessas instituições, com intuito de apresentar novas possibilidades e facilitar o processo ensino-aprendizagem de seus alunos.

As instituições museológicas participam na formação inicial de professores, funcionando como locais para a realização de estágios curriculares, mesmo que não respaldados pela legislação que valida os mesmos (CARVALHO, 2009; OVIGLI, 2009). De acordo com Jacobucci, contribuem também para a formação continuada de professores, por meio de diversas ações, que, porém, não são reguladas ou avaliadas por instâncias educacionais competentes. Nesse sentido, a autora afirma que "a formação de professores está sendo assumida por esses espaços e, ao fazêlo, essas instituições passam a exercer uma função social que deve ser desempenhada com a máxima responsabilidade" (JACOBUCCI, 2007, p. 17).

Apesar de os museus serem espaços complementares interessantes para a formação de professores, existe um distanciamento entre eles e as universidades, o que limita o estabelecimento de parcerias. De acordo com pesquisa realizada por Mahomed e Falcão (2009), professores que atuam em licenciaturas relatam que isso se deve a: falta de informação, tempo e apoio operacional, além de um 
distanciamento de natureza acadêmica entre as duas instituições.

A relação entre museu, universidade e escola, no que diz respeito à formação de profissionais de educação, têm diversas facetas e pode ser profícua para todos os envolvidos.

O cuidado com a formação de mediadores tornou-se tema obrigatório nos museus de ciências e faz parte de um processo de formação continuada em muitos deles; é tema de pesquisas em várias instituições museais brasileiras; vem sendo proposta como disciplina curricular em cursos de formação de professores de ciências/biologia, em universidades federais [...] enquanto muitos museus encontram ainda dificuldades para formar regularmente seus mediadores. (RIBEIRO; FRUCCHI, 2007, p. 70)

É interessante considerar uma possível contribuição das licenciaturas na formação de profissionais qualificados para atuarem em museus, levando-se em conta que há uma carência de cursos específicos que capacitem para a educação não formal (GUIMARÃES; VASCONCELOS, 2006). Conhecendo a intencionalidade dos museus ou das instituições culturais afins, bem como as dimensões de sua pedagogia, existe a possibilidade de que as licenciaturas e os cursos de pedagogia sejam celeiros para a formação de um futuro profissional de educação em museus.

O presente trabalho procura fomentar a discussão a respeito das possíveis articulações entre educação formal e não formal para a formação de profissionais de educação. Tem como objetivo analisar processos de formação de mediadores em museus de ciência, assim como discutir a contribuição da formação acadêmica em educação para a complementação desses processos.

\section{2 - Os saberes docentes como referencial de análise}

As pesquisas em educação em museus, por constituírem uma área recente, ainda carecem de referenciais teóricos próprios, e a sua construção representa um de seus principais desafios. Assim, muitos pesquisadores dessa área vêm utilizando, por meio de adaptações, referenciais provenientes do campo da educação, originalmente aplicados a espaços de educação formal (MARANDINO, 2006).

Nesta investigação, pretende-se seguir o mesmo caminho, abordando a questão formação de mediadores de museus, tendo como referência os saberes docentes, na concepção de Maurice Tardif. Outras pesquisas, que consideram semelhanças entre o trabalho docente e o de mediação, utilizaram os saberes 
docentes como referência para tratar questões referentes a práticas educativas em museus (ROCHA, 2011; OVIGLI, 2009; SOARES, 2003).

Historicamente, os estudos sobre os saberes docentes têm relação com um movimento de profissionalização do magistério, sobretudo nos Estados Unidos da América, na década de 1980, incluindo o interesse pelo estabelecimento de um repertório de conhecimentos profissionais para o ensino e o entendimento da natureza desses conhecimentos. A questão tem grande relevância para as pesquisas em ciências da educação nos Estados Unidos desde essa época, na Europa a partir da década de 1990 e, mais recentemente, na América Latina, especialmente no Brasil (BORGES; TARDIF, 2001; TARDIF, 2010). Nesse contexto,

As produções a respeito da temática saberes docentes têm ocupado papel de destaque na formação de professores, o que é atribuído, em grande parte, ao seu potencial no desenvolvimento de ações formativas que vão além de uma abordagem acadêmica, envolvendo as dimensões pessoal, profissional e organizacional da profissão docente. (ALMEIDA; BIAJONE, 2007, p. 283)

Tardif (2010) reúne textos que representam diferentes etapas das pesquisas realizadas, ao longo de mais de uma década de reflexão, a respeito dos saberes docentes e a formação de professores. O autor procura identificar e compreender a natureza dos saberes que servem de base à prática dos professores, construindo um modelo a partir de categorias dos próprios docentes. Situa o professor como produtor de saberes e não apenas transmissor dos saberes produzidos por outros grupos.

Para o autor, o saber dos professores é plural e heterogêneo: por ser composto de conhecimentos e um saber-fazer com distintas naturezas e origens; por ser pautado em diferentes teorias, concepções e técnicas; e por atender a demandas de uma prática heterogênea. O saber docente provém, além das experiências individuais, da formação para o magistério na universidade, dos programas escolares e da experiência em sala de aula. Assim, o autor considera que esse é composto de: os saberes da formação profissional, os saberes disciplinares, o saberes curriculares e os saberes da experiência.

Os saberes da formação profissional, ancorados nas ciências humanas e da educação, são transmitidos pelas instituições de formação de professores. Segundo o autor, são:

saberes destinados à formação científica ou erudita dos professores [...] apresentamse como doutrinas ou concepções provenientes de reflexões sobre a prática 
educativa no sentido amplo do termo, reflexões racionais e normativas que conduzem a sistemas mais ou menos coerentes de representação e de orientação da atividade educativa. (TARDIF, 2010, p. 37)

Por sua vez, os saberes disciplinares correspondem a diversos campos do conhecimento, como, por exemplo, matemática, física, história e se encontram sob a forma de disciplinas, nos diversos cursos universitários. Nas palavras do autor,

a prática docente incorpora [...] saberes sociais definidos e selecionados pela instituição universitária. [...] correspondem aos diversos campos do conhecimento, aos saberes que dispõe nossa sociedade, tais quais se encontram hoje integrados nas universidades, sob forma de disciplinas [...] são transmitidos nos cursos e departamentos universitários, independentes das faculdades de educação e dos cursos de formação de professores. (TARDIF, 2010, p. 38)

Os saberes curriculares remetem aos discursos, objetivos, conteúdos e métodos definidos pela instituição escolar. Apresentam-se sob a forma de programas escolares que balizam a prática docente. Ou seja, esses saberes

correspondem aos discursos, objetivos, conteúdos e métodos, a partir dos quais a instituição escolar categoriza e apresenta os saberes sociais por ela definidos e selecionados como modelos da cultura erudita e de formação para a cultura erudita. Apresentam-se concretamente sob a forma de programas escolares que os professores devem aprender a aplicar. (TARDIF, 2010, p. 38)

Os professores desenvolvem ainda, ao longo do tempo, saberes particulares

que não têm origem na universidade ou no currículo e não são sistematizados, mas provêm e são constituintes da prática, aos quais Tardif (2010) denomina saberes da experiência. Nesse sentido,

os próprios professores, no exercício de suas funções e na prática de sua profissão, desenvolvem saberes específicos, baseados em seu trabalho cotidiano e no conhecimento de seu meio [...] brotam da experiência e são por ela validados. Eles incorporam-se à experiência individual e coletiva sob a forma de habitus e habilidades, de saber-fazer e saber-ser. (TARDIF, 2010, p. 38)

Segundo o autor, os professores consideram os saberes da experiência o fundamento de sua competência profissional, o que lhes permite lidar com situações concretas do seu cotidiano em sala de aula, que requerem habilidade de improvisação. O autor ressalta que, mesmo vinculados à subjetividade e individualidade do professor, o saber proveniente da experiência só adquire objetividade quando compartilhado, o que frequentemente ocorre no dia a dia do ambiente escolar.

Em sua obra, Tardif (2010) investiga os saberes nos quais os professores baseiam a sua prática, no contexto específico da escola, compreendendo-os como 
sujeitos dotados e produtores de saberes múltiplos, provenientes de diferentes fontes. Na presente pesquisa, tratar-se-ão de processos educativos que ocorrem nos museus de ciências, buscando entender, a partir desse referencial, os saberes enfatizados durante a formação de mediadores nesses espaços. Entende-se, no entanto, que há limites nessa abordagem e necessidade de adaptações, devido aos diferentes contextos em que se desenvolvem os processos estudados.

A respeito de os saberes docentes, compostos por saberes disciplinares, curriculares, da formação profissional e da experiência, pode-se afirmar que

o professor ideal é alguém que deve conhecer sua matéria, sua disciplina e seu programa, além de possuir certos conhecimentos relativos às ciências da educação e à pedagogia e desenvolver um saber prático baseado em sua experiência cotidiana com os alunos. (TARDIF, 2010, p.39)

Buscando aproximações entre essa descrição do "professor ideal" e um mediador de museus, podem ser enumerados atributos interessantes à prática de mediação, compreendendo-os a partir das categorias estabelecidas por Tardif (2010).

É útil a um mediador ter domínio acerca dos conteúdos temáticos presentes, implícita ou explicitamente, nas exposições em que trabalha como, por exemplo: biologia (em um uma exposição sobre biodiversidade), física (em um museu de astronomia), história da arte (em um museu de arte). Conhecer tais conteúdos é condição essencial para que esse profissional não seja um transmissor de informações previamente selecionadas por outros, mas um verdadeiro mediador que, dotado desse conhecimento, conduz o diálogo com o público, a partir de suas próprias indagações. Em outras palavras, o mediador idealmente precisa mobilizar um saber disciplinar. Por outro lado, não lhe é suficiente conhecer os saberes provenientes das ciências de referência contidos nas exposições. Se a intenção não for apenas apresentar uma visão de especialista, mas provocar o interesse sobre as temáticas propostas, é imprescindível que ele detenha as ferramentas que propiciem efetiva comunicação com diferentes tipos de público. Compreende-se o mediador como um educador, que, portanto, enriqueceria sua prática, ao deter conhecimentos provenientes das ciências da educação. Reconhece-se, dessa forma, o saber da formação profissional.

Tardif (2010) considera que o professor em sua prática é influenciado por normas, discursos, objetivos, que orientam a instituição escolar na seleção dos 
saberes sociais a serem apresentados por ela. A prática do mediador no museu, assim como a do professor, é conduzida em uma instituição com uma história, regras, propostas museológica e educativa, que a influenciam e podem ser compreendidos como um saber curricular.

A respeito dos saberes da experiência, o autor propõe que são construídos e estão a serviço de um contexto de múltiplas interações, às quais os professores estão submetidos. Assim, mobilizam saberes que os permitem enfrentar situações imprevistas típicas de sua profissão, os quais são desenvolvidos na prática, ao lidar com tais situações.

No exercício cotidiano de sua profissão, os condicionantes aparecem relacionados a situações concretas que não são passíveis de definições acabadas, que exigem improvisação e habilidade pessoal, bem como a capacidade de enfrentar situações mais ou menos transitórias e variáveis. Ora, lidar com condicionantes e situações é formador: somente isso permite ao docente desenvolver o habitus [...] que the permitirão justamente enfrentar os condicionantes imponderáveis de sua profissão. (TARDIF, 2010, p. 49)

Compreende-se que, no museu, guardadas as suas especificidades, ocorre 0 mesmo processo. De acordo com Marandino (2008), o educador de museus, no exercício de sua prática, convive com imprevisibilidades, as quais devem superar por meio da improvisação, devido à heterogeneidade do público e à complexidade de sua função. Nesse mesmo sentido, Queiroz (2003) considera que a prática de um educador de museus, envolve um talento artístico, necessário à superação de tais situações inusitadas inerentes à sua relação com o público. Esses profissionais devem ter a capacidade de refletir durante suas ações e, para isso, mobilizam saberes da experiência.

Apesar das semelhanças entre a prática educativa de docentes e em museus, é importante ressaltar ainda que o trabalho de mediação relaciona-se a saberes próprios, que não são apenas disciplinares, pedagógicos, curriculares e da experiência. Queiroz et al. (2002) identificaram os saberes da mediação, dentre os quais alguns comuns à escola e ao museu, e outros próprios dos museus, como descrito a seguir:

I) saberes compartilhados com a escola - saber disciplinar, saber da transposição didática, saber do diálogo e saber da linguagem; II) saberes compartilhados com a escola, no que dizem respeito à educação em ciência - saber da história da ciência, saber da visão de ciência, saber das concepções alternativas; III) saberes mais propriamente de museus - saber da história de instituição, saber da interação com professores, saber da conexão, saber da história da humanidade, saber da 
expressão corporal, saber da manipulação, saber da ambientação e saber da concepção da exposição. (QUEIROZ et al., 2002, p. 81)

\section{3 - Procedimentos metodológicos}

O presente trabalho tem como foco os processos de formação de mediadores em museus de ciência, situando-se como uma pesquisa na área de educação em museus, a qual vem se expandindo no Brasil desde a década de 90 do século $\mathrm{XX}$ (MARANDINO et al., 2009).

A questão será abordada a partir da descrição e análise de ações promovidas para formação de mediadores, assim como de suas concepções a respeito de sua própria formação. A coleta de dados foi conduzida no Museu Espaço Ciência Viva (ECV) e no Museu de Astronomia e Ciências Afins (Mast), cujas equipes de mediadores, em sua grande maioria, eram compostas por estudantes de graduação em diversas licenciaturas, assim como estudantes de cursos de formação para o magistério em nível médio.

Foram identificados e descritos dois tipos de ações para formação de mediadores, às quais se denominou ações de formação inicial e ações de formação em serviço, respectivamente definidas como: ações promovidas pelo museu antes de o mediador iniciar a trabalhar com o público e ações realizadas posteriormente.

As ações de formação inicial foram descritas a partir da observação dos cursos de curta duração, organizados pelo ECV e pelo Mast, no início do ano de 2012: "Curso de capacitação de mediadores para atuação em ambientes de ensino não formal" e "Mediação em museus e centros de ciência: teoria e prática".

Durante as observações, as falas dos responsáveis pelas atividades dos cursos foram gravadas em áudio, e se fez uso de roteiros que permitiram o registro: das metodologias adotadas, dos principais temas abordados e do perfil dos responsáveis. Constavam também, nos roteiros, tópicos a serem identificados nas discussões ocorridas durante cada atividade, que se referiram aos diferentes saberes abordados nos cursos. São eles: conceitos específicos dos saberes de referência; história do museu; objetivos educativos do museu; tipos de público a serem atendidos; conceitos da área de educação e/ou educação em museus; aspectos pedagógicos relativos ao atendimento ao público; prática de mediação (exemplos de experiências anteriores). 
Em uma segunda etapa da coleta de dados, foram feitas entrevistas semiestruturadas, com o chefe da Coordenação de Educação do Mast e um dos vice-presidentes do ECV, os quais participam da concepção e execução dos cursos de formação de mediadores observados, assim como das ações de formação em serviço propostas pelos museus. As entrevistas possibilitaram a descrição dessas ações, assim como um maior detalhamento dos cursos já mencionados.

A última etapa da coleta de dados consistiu na aplicação de questionários com os mediadores do ECV e do Mast, que eram autoaplicáveis e foram entregues em mãos ou enviados por correio eletrônico. Os questionários permitiram coleta de dados sobre concepções dos mediadores a respeito de sua formação profissional, no que se refere à contribuição da sua formação acadêmica prévia em nível de ensino médio e graduação ${ }^{3}$. Esse aspecto foi acessado por meio de uma questão aberta, cujas respostas foram organizadas em categorias de análise para elaboração das interpretações apresentadas.

A pesquisa abrangeu todos os mediadores com algum tipo de vínculo formal ${ }^{4}$ com as instituições: bolsistas de ensino médio, graduandos e graduados e, no caso do ECV, também alunos em formação para o magistério, que realizam estágio supervisionado no museu, através de parceria com a Escola Municipal Julia Kubitschek.

\section{4 - Breve descrição do Museu Espaço Ciência Viva}

O ECV, organizado juridicamente como uma sociedade civil sem fins lucrativos, foi fundado em 1983, por um grupo de cientistas, pesquisadores e educadores. O objetivo da instituição é a "[...] divulgação e a desmistificação da ciência, tornando-a acessível [...], bem como a melhoria da qualidade do ensino de ciências e da matemática" (COUTINHO-SILVA et al., 2005, p. 24).

\footnotetext{
3 Nos questionários, constavam outras questões que não serão discutidas em detalhe no âmbito deste trabalho, incluindo o perfil dos mediadores em termos de sexo, idade, escolaridade, tipo de graduação.

4 No ECV: Coordenação de Aperfeiçoamento de Pessoal do Nível Superior (Capes); Programa Institucional de bolsas de extensão da Universidade Federal do Rio de Janeiro (Pibex/UFRJ) e Programa de bolsas-auxílio para Atividades Discentes da Universidade Estadual do Rio de Janeiro (Uerj).

No Mast: Conselho Nacional de Desenvolvimento Científico e Tecnológico (CNPq): Programa Institucional de Bolsas de Iniciação Científica para o Ensino Médio (Pibic-EM); Programa Institucional de Bolsas de Iniciação Científica (Pibic) e Programa de Capacitação Institucional (PCl)/ Centro de Integração empresa-escola.
} 
O museu oferece ao seu público escolar e não escolar exposição permanente, composta de cerca de 60 módulos, que tratam de diversas temáticas relacionadas a áreas como: física, matemática, biologia, astronomia, dentre outros. Propõe-se, dessa forma, a aproximar a ciência do público, por meio de experimentos lúdicos e interativos.

\section{5 - Breve descrição do Museu de Astronomia e Ciências Afins}

O Mast, fundado em 1985, tem como missão atualmente: "ampliar o acesso da sociedade ao conhecimento científico e tecnológico por meio da pesquisa, preservação de acervos, divulgação e história da ciência e da tecnologia no Brasil" (MUSEU DE ASTRONOMIA E CIÊNCIAS AFINS, 2010, p. 11).

O acervo museológico do Mast é composto por mais de dois mil objetos, destacando-se a coleção de instrumentos científicos oriundos do Observatório Nacional. Nos campos da divulgação da ciência e educação em museus, o Mast realiza ações, tais quais: o programa observação do céu, atividades itinerantes de divulgação da ciência, visitação mediada, cursos de formação continuada de professores, dentre outras 5 .

\section{6 - Resultados}

\section{1 - Práticas e saberes na formação de mediadores}

Os processos de formação de mediadores no ECV e no Mast apresentaram semelhanças, no sentido da estruturação das ações, incluindo um curso de curta duração, realizado no início de cada ano, e diversas ações de formação em serviço, como é comum em vários museus de ciência (MASSARANl; MERZAGORA; RODARI, 2009).

As propostas educativas dos cursos de formação inicial consistiram em fornecer aos mediadores novatos ferramentas básicas que lhes permitissem executar seu trabalho, numa abordagem teórica e prática. Durante esses cursos, foram apresentadas as atividades que os museus disponibilizam ao seu público e conteúdos teóricos das ciências de referência associados às mesmas e da educação em museus. A formação nos museus estudados se deu de maneira contínua após os cursos, por meio das seguintes ações de formação em serviço:

5 As informações a respeito do acervo do Mast e de sua organização administrativa foram consultadas em <www.mast.br>. Acesso em 15/06/2014 
observação da atuação de mediadores experientes; capacitações pontuais para atividades específicas; reuniões periódicas; estudo orientado; participação em cursos externos, palestras e seminários.

O "Curso de capacitação de mediadores para atuação em ambientes de ensino não formal", organizado pelo ECV, teve duração de aproximadamente 18 horas, quando foram realizadas as atividades apresentadas a seguir (Quadro 1).

\section{Quadro 1: Atividades do "Curso de capacitação de mediadores para atuação em ambientes de ensino não formal"}

\begin{tabular}{|c|c|c|}
\hline ATIVIDADE & PRINCIPAIS TEMÁTICAS & METODOLOGIAS \\
\hline Abertura do curso & $\begin{array}{l}\text { O Espaço Ciência Viva: } \\
\text { história, objetivos e referenciais } \\
\text { teóricos }\end{array}$ & $\begin{array}{l}\text { Apresentação oral com auxílio } \\
\text { de PowerPoint }\end{array}$ \\
\hline Arte com sucata & Reciclagem de materiais & Atividade prática \\
\hline $\begin{array}{l}\text { Divulgando saberes de } 6 \text { a } \\
12 \text { anos }\end{array}$ & Educação Infantil & $\begin{array}{l}\text { Apresentação oral com auxílio } \\
\text { de PowerPoint e dinâmica de } \\
\text { grupo }\end{array}$ \\
\hline Trabalhando com o sangue I & $\begin{array}{l}\text { Biologia (Sistema Circulatório } \\
\text { Humano) }\end{array}$ & $\begin{array}{l}\text { Apresentação oral e Atividade } \\
\text { prática }\end{array}$ \\
\hline Brincando com a Biologia & Biologia (Genética) & Atividade prática \\
\hline Trabalhando com o sangue II & $\begin{array}{l}\text { Biologia (Sistema Circulatório } \\
\text { Humano) }\end{array}$ & Atividade prática \\
\hline Ciência e Arte & $\begin{array}{l}\text { Biologia (Citologia) e Arte- } \\
\text { Educação }\end{array}$ & Atividade prática \\
\hline Faça você mesmo & Biologia (Microscopia) & Atividade prática \\
\hline Física nas cores & Física (Óptica) & $\begin{array}{l}\text { Apresentação oral e Atividade } \\
\text { prática }\end{array}$ \\
\hline $\begin{array}{l}\text { Conhecendo os Micro- } \\
\text { organismos }\end{array}$ & Biologia (Microbiologia) & $\begin{array}{l}\text { Apresentação de vídeo e } \\
\text { atividade prática }\end{array}$ \\
\hline Sexualidade & $\begin{array}{l}\text { Biologia (Sistema Reprodutivo } \\
\text { Humano e DSTs) e Psicologia }\end{array}$ & Discussão em grupo \\
\hline
\end{tabular}

Observa-se no Quadro 1 que, dentre as atividades realizadas no curso de mediadores do ECV, apenas uma não tratou de conceitos relacionados à química, física ou biologia, ciências frequentemente abordadas nas atividades de divulgação científica desse museu. Entende-se que houve, nesse caso, uma ênfase em saberes disciplinares, fato que também se refletiu no perfil dos responsáveis pela condução 
das atividades, os quais, frequentemente, eram pesquisadores em áreas relacionadas aos temas abordados. O teor disciplinar do discurso desses pesquisadores pôde ser identificado, por exemplo, nas falas a seguir, registradas durante o curso:

Vamos mergulhar dentro dessa célula, e a primeira estrutura que a gente vai encontrar [...] é a membrana plasmática. [...]. A membrana é formada de fosfolipídios [...]. Não é totalmente hidrofóbica, ela tem uma parte hidrofílica [...]. E essas coisas roxas são proteínas que estão embebidas nessa membrana. (CURSO ECV - Na atividade "Ciência e Arte", durante apresentação de vídeo, 26/03/2012).

Alguns micro-organismos [...] não crescem em meios de cultura normais. Por exemplo, uma levedura, um fungo, ele precisa de um meio de cultura específico (que) a gente chama [...] de saporoma [...]. Eu, por exemplo, trabalho com Leishmania [...] (que) precisa de um meio específico, [...] de soro fetal bovino, para [...] crescer. (CURSO ECV - Na atividade "Microbiologia", durante apresentação em PowerPoint, 29/03/2012)

Os saberes disciplinares permanecem em destaque nas ações de formação em serviço empreendidas pelo ECV. Pretende-se que haja uma complementação teórica dos conteúdos das ciências de referência, úteis à prática de mediação, após o curso. Essa complementação se dá por meio de diferentes estratégias, como oficinas realizadas ao longo do ano, estudo individual e coletivo e reuniões com pesquisadores.

A presença desse tipo de saber nos processos formativos analisados relaciona-se às próprias finalidades dos museus estudados, no que diz respeito ao seu vínculo com a divulgação da ciência. Os saberes disciplinares são peças importantes para a formação de mediadores, o que condiz com concepção de mediação adotada no ECV. Nessa instituição, se espera que os mediadores se portem como facilitadores de um diálogo com o público, pautado em suas próprias motivações, como proposto abaixo:

No fundo, você quer que eles (os mediadores) tenham a capacidade de se comportar de maneiras diferentes dependendo da situação. $E$ isso exige uma maturidade, precisa treinamento do indivíduo, [...] E no museu, a gente quer que ele tenha essa outra postura. Não um sujeito capaz de reproduzir informação, mas um sujeito capaz de ajudar alguém a construir um conceito novo. (depoimento, vice-presidente do EVC $\left.^{6}, 29 / 08 / 2012\right)$

Para tal, um conhecimento abrangente dos temas tratados se faz necessário, na medida em que permite aos mediadores lidarem com questionamentos, variados e imprevistos, dos visitantes. Os saberes disciplinares conferem uma flexibilidade,

\footnotetext{
${ }^{6}$ Optamos por manter o anonimato dos entrevistados.
} 
que Ihes possibilita propor relações entre os conceitos científicos abordados e questões controversas, cotidianas, dentre outras que sejam de interesse do público.

No caso do Mast, os saberes disciplinares tiveram menor destaque. O curso de formação de , "Mediação em museus e centros de ciência: teoria e prática", pautou-se por uma abordagem mais teórica de assuntos pertinentes à educação em museus. O objetivo do curso, de acordo com a sua programação, foi "capacitar mediadores de museus e centros de ciência, a partir da discussão de teorias educacionais e saberes envolvidos nas práticas de mediação" (Quadro 2).

\section{Quadro 2: Atividades do curso "Mediação em museus e centros de ciência: teoria e prática"}

\begin{tabular}{|c|c|c|}
\hline ATIVIDADES & PRINCIPAIS TEMÁTICAS & METODOLOGIAS \\
\hline Audiências em museus & $\begin{array}{l}\text { Estudos de público e } \\
\text { avaliação em museus }\end{array}$ & $\begin{array}{l}\text { Apresentação oral com } \\
\text { auxílio de PowerPoint }\end{array}$ \\
\hline $\begin{array}{l}\text { Educação em museus e espaços } \\
\text { não formais }\end{array}$ & $\begin{array}{l}\text { A função educativa dos } \\
\text { museus de ciências em uma } \\
\text { abordagem histórica }\end{array}$ & $\begin{array}{l}\text { Apresentação oral com } \\
\text { auxílio de PowerPoint }\end{array}$ \\
\hline Trilhas educativas do Mast & $\begin{array}{l}\text { Relação museu-escola: } \\
\text { experiência do Mast }\end{array}$ & $\begin{array}{l}\text { Apresentação oral com } \\
\text { auxílio de PowerPoint }\end{array}$ \\
\hline $\begin{array}{l}\text { Tecendo Redes por um planeta } \\
\text { saudável }\end{array}$ & $\begin{array}{l}\text { Relação museu-escola: } \\
\text { experiência do Museu da } \\
\text { Vida }\end{array}$ & $\begin{array}{l}\text { Apresentação oral com } \\
\text { auxílio de PowerPoint }\end{array}$ \\
\hline Mediação em museus & $\begin{array}{l}\text { Mediação em museus: } \\
\text { conceitos, finalidades e } \\
\text { características }\end{array}$ & $\begin{array}{l}\text { Apresentação oral com } \\
\text { auxílio de PowerPoint }\end{array}$ \\
\hline Saberes da mediação & $\begin{array}{l}\text { Mediação em museus: } \\
\text { conceitos, finalidades e } \\
\text { características }\end{array}$ & Discussão em grupo \\
\hline $\begin{array}{l}\text { Processo de tomada de decisão } \\
\text { na mediação "Brincando de } \\
\text { Matemático" }\end{array}$ & $\begin{array}{l}\text { Aprendizagem, motivação e } \\
\text { mediação em museus }\end{array}$ & $\begin{array}{l}\text { Apresentação oral com } \\
\text { auxílio de PowerPoint }\end{array}$ \\
\hline $\begin{array}{l}\text { Mediação segundo os } \\
\text { mediadores }\end{array}$ & $\begin{array}{l}\text { Experiências de mediação } \\
\text { em museus }\end{array}$ & Discussão em grupo \\
\hline $\begin{array}{l}\text { Aparatos interativos em } \\
\text { exposições }\end{array}$ & $\begin{array}{l}\text { Interatividade em museus de } \\
\text { ciências }\end{array}$ & $\begin{array}{l}\text { Apresentação oral com } \\
\text { auxílio de PowerPoint }\end{array}$ \\
\hline $\begin{array}{l}\text { Exposição: "Olhar o céu, medir a } \\
\text { Terra" }\end{array}$ & $\begin{array}{l}\text { Concepção e montagem de } \\
\text { exposições }\end{array}$ & $\begin{array}{l}\text { Apresentação oral com } \\
\text { auxílio de PowerPoint }\end{array}$ \\
\hline Oficina de mediação & $\begin{array}{l}\text { Experiências de mediação } \\
\text { em museus }\end{array}$ & $\begin{array}{l}\text { Visita a exposições e } \\
\text { discussão em grupo }\end{array}$ \\
\hline Programa de Observação do Céu I & Astronomia & Apresentação oral \\
\hline Planetário Inflável & Astronomia & Atividade prática \\
\hline
\end{tabular}

Revista Educação Online, n. 16, mai-ago 2014, p. 1-22. 


\begin{tabular}{|l|l|l||}
\hline Programa de Observação do Céu II & Astronomia & Atividade prática \\
\hline
\end{tabular}

As teorias que servem de referência às ações educativas conduzidas em museus foram a base do curso do Mast. No entanto, a despeito do caráter teórico, observou-se uma preocupação com a aplicabilidade prática das teorias e conceitos abordados. Traçando um paralelo com as ideias de Tardif (2010), considera-se que essa abordagem enfatizou saberes da formação profissional ou "das ciências da educação":

saberes transmitidos pelas instituições de formação de professores (que) [...] não se limitam a produzir conhecimentos, mas procuram também incorporá-las à prática do professor. [...] Esses conhecimentos se transformam em saberes destinados à formação científica ou erudita dos professores. (TARDIF, 2010, p. 37)

$\mathrm{Na}$ formação em serviço, essa ênfase nos saberes da formação profissional permanece. Por meio de estudo, participação em palestras e reuniões de avaliação, pretende-se que o mediador, ao longo do tempo, aproprie-se de teorias que servem de alicerce à prática educativa em museus.

Nos processos de formação de mediadores no Mast, portanto, fez-se uso de conhecimentos produzidos no âmbito das pesquisas em educação em museus e de outros campos correlatos, buscando fundamentar a prática futura de seus mediadores com saberes da formação profissional, como ilustrado pelas falas a seguir:

Nós vamos falar hoje da proposta metodológica que chama "Trilhas educativas entre - Mast e a escola", que é uma atividade [...] da visita escolar ao Museu de Astronomia. [...] A gente vai apresentar primeiro alguns estudos da área que tenham a ver com mediação, visitas orientadas, visitas escolares [...] e depois [...] falar do caso do Mast. (apresentação oral, CURSO MAST - Na atividade "Trilhas Educativas do Mast", 24/01/2012)

Hoje a gente ficou incumbido de falar [...] sobre os saberes da mediação. Especificamente desse artigo [...] da Gloria Queiroz. [...]. O artigo tem o objetivo de saber o que o mediador [...] tem que se apropriar para saber lidar com o público [...]. Então, a gente vai simular aqui algumas mediações [...]. Vocês vão [...] categorizar os nossos saberes [...]. A ideia é a gente mostrar um pouco desses saberes que são discutidos no artigo e depois fazer uma prática (CURSO MAST, atividade "Saberes da Mediação", 25/01/2012)

Essa relação da prática com a pesquisa está presente nas próprias finalidades da Coordenação em Educação em Ciências do Mast, onde se realizam estudos acadêmicos desde 1996, com objetivo de avaliar suas atividades 
educacionais (CAZELLI; COIMBRA, 2010). Esses estudos, muitas vezes, acontecem com a participação dos próprios mediadores, que, em grande parte, são bolsistas do $\mathrm{CNPq}^{7}$, vinculados a projetos de pesquisa. Assim, é natural que a produção científica na área de educação em museus seja considerada um aspecto pertinente também à formação de mediadores nessa instituição.

No caso do Mast, não houve uma ênfase nos saberes disciplinares. Temáticas relativas à astronomia e física, dentre outras que servem de referência às atividades voltadas para o público no museu, tiveram menor destaque do que os conteúdos relativos aos saberes da formação profissional, diferentemente do que ocorreu no ECV.

Em ambos os museus, os saberes da experiência foram fortemente valorizados. O próprio exercício da mediação foi considerado elemento constituinte da formação de um mediador nessas instituições. Isso significa considerar que os saberes que fundamentam o trabalho de um mediador são também adquiridos e aprimorados ao longo do tempo, com a prática, a partir da relação com o público, como propõe o vice-presidente do ECV:

Por uma questão de limitação, é um curso condensado (Curso de capacitação de mediadores para atuação em ambientes de ensino não formal) [...]. Então eu diria (que seu objetivo é): iniciar um processo [...] E acreditar que eles vão continuar com esse processo de aprendizagem, de amadurecimento em exercício, atuando. (depoimento, 28/12/2012)

Nessa mesma direção, no Mast, entende-se que a formação de um mediador não se esgota em ações localizadas como o curso de mediadores e leva tempo, pois Isso é paulatino. [...] a gente observa, nesse trabalho de mediação, verdadeiras transformações. Por exemplo, há mediadores que já são intrinsecamente extrovertidos. Há outros que não [...], e o tempo vai passando, e essa pessoa vai se 'empoderando', até se sentir à vontade. Isso pode levar mais tempo ou menos tempo. Então [...] é preciso haver uma sensibilidade para respeitar esses tempos. (depoimento, nome, chefe da Coordenação de Educação do Mast, 13/12/2012)

A prática é um dos fundamentos também da formação de professores, e, nesse sentido, os saberes da experiência têm papel primordial. Tardif (2010) os define, de forma pertinente, como "saberes práticos":

Conjunto de saberes atualizados, adquiridos e necessários no âmbito da prática da profissão docente e que não provêm das instituições de formação nem dos

\footnotetext{
7 Conselho Nacional de Desenvolvimento Científico e Tecnológico (CNPq): Programa Institucional de Bolsas de Iniciação Científica para o Ensino Médio (Pibic-EM); Programa Institucional de Bolsas de Iniciação Científica (Pibic) e Programa de Capacitação Institucional (PCl).
} 
1currículos. [...] São saberes práticos, [...] se integram a ela e dela são constituintes enquanto prática docente. [...] Eles constituem [...] a cultura docente em ação. (TARDIF, 2010, p. 48)

Para o autor, os saberes da experiência não são acumulados apenas individualmente, mas compartilhadas por meio da relação entre os pares, ou seja, da experiência coletiva. A partir dela, é possível criar mecanismos para sistematização e objetivação desses saberes, em cursos de formação de docentes, através do relacionamento entre jovens professores e os mais experientes, por exemplo.

A troca de experiências tem papel fundamental nos processos de formação de analisados no ECV e no Mast. A presença de mediadores experientes na condução de diversas atividades dos cursos de mediadores possibilitou o compartilhamento de estratégias de mediação e discussão de variados aspectos práticos do trabalho. De maneira mais abrengente, o diálogo entre os pares se mantém como uma estratégia permanente de formação nos museus em questão, com mediadores mais antigos supervisionando e apoiando a atuação dos mais novos constantemente.

\section{2 - Considerações sobre o papel da formação acadêmica na formação de mediadores}

A mobilização de saberes disciplinares, da formação profissional e da experiência é importante na formação de mediadores nos museus, embora existam lacunas nos processos de formação analisados e um desequilíbrio entre os diferentes saberes enfatizados nos casos estudados.

O ECV e o Mast promovem, anualmente ou semestralmente, cursos de formação inicial, mas, devido à grande rotatividade nas equipes, com ingresso de mediadores nos museus ao longo de todo o ano, nem todos participam desses cursos antes de começar a trabalhar efetivamente. Por sua vez, as ações de formação em serviço, são realizadas sem um planejamento minucioso e com um caráter não obrigatório.

Compreende-se que esses museus não dispõem de capacidade operacional, para cumprirem de forma exclusiva o papel de formadores dos profissionais em questão. Dado que a grande maioria deles provém de cursos de formação de professores, magistério e licenciaturas, é importante considerar de que forma eles 
podem contribuir para a formação de educadores aptos a trabalharem também nessas instituições.

A presente pesquisa analisou essa questão, a partir da perspectiva dos próprios mediadores, por meio de dados provenientes de questionários, respondidos por 32 mediadores do ECV e 17 do Mast. Os mediadores foram indagados sobre o que valorizam na sua formação, partindo-se do princípio de que a atividade de mediação envolve diversos saberes, e que a formação desses profissionais é influenciada por múltiplos fatores. Foi proposta a seguinte questão: "O que você aprendeu na faculdade (ou no ensino médio) contribui para o seu trabalho como mediador? Por quê?".

Dos 31 mediadores do ECV que responderam à questão mencionada, 27 reconhecem contribuição de seus estudos no ensino médio ou na graduação para a sua atuação profissional no museu. Nota-se que grande parte dos mediadores (17) considera que sua formação acadêmica contribui para o seu trabalho, principalmente por dois tipos de fatores: aqueles relacionados a conhecimentos e práticas na área de educação (10) e os relativos a conteúdos das ciências de referência abordadas no museu (7). Ou seja, relacionam essa contribuição à aquisição e aprimoramento de saberes da formação profissional e disciplinar. Os mediadores relataram, frequentemente, questões relativas a um desses dois aspectos, como exemplificado abaixo:

Porque na faculdade tive a oportunidade de estudar sobre educação, na verdade [...] trago muito do que aprendi para o museu [...] penso que dialogar com outros saberes é sempre válido. (depoimento, mediador 29 - ECV, outubro de 2012)

Há muitos conceitos de óptica, acústica, rotações e outros conteúdos da faculdade que me permitiram entender mais a fundo o funcionamento de alguns módulos de física. (depoimento, mediador 17 - ECV, outubro de 2012)

Dez mediadores relacionaram a contribuição da sua formação acadêmica ao seu trabalho e aos conhecimentos adquiridos na área de educação. Desses, oito cursam o ensino médio. Nesse sentido, é importante ressaltar que os mediadores de ensino médio do ECV são todos (15) provenientes de uma escola de formação de professores. Grande parte deles, portanto, considera sua formação pedagógica como importante para seu trabalho no museu e destacam o desenvolvimento, durante a formação acadêmica prévia, de capacidades relacionadas à interação com o público, como a seguir: 
Porque mediar não é só falar e despejar o assunto, mas é também interagir com o público e fazer com que eles se sintam seguros, fazer eles acharem a resposta para a sua própria pergunta. A função do professor é bem parecida. (depoimento, mediador 12 - ECV, outubro de 2012)

A exemplo do caso do ECV, a maioria dos mediadores do Mast considera que a sua formação acadêmica prévia contribui para seu trabalho no museu (14 de 17), sobretudo no que se refere a saberes da formação profissional e disciplinares. Segundo eles, essa contribuição se dá principalmente por três fatores, relacionados às disciplinas cursadas nas graduações: o conhecimento de conceitos referentes às ciências tratados no Mast, como a astronomia (4); os conhecimentos teóricos e práticos em educação (3); e o conhecimento sobre outros temas pertinentes a sua atuação como profissionais de museus de ciência, como a divulgação da ciência, a história e a filosofia da ciência e as relações entre ciência, tecnologia e sociedade (3). Nas palavras dos mediadores,

Meu conhecimento científico, principalmente na área da química, me ajudou a entender sobre astronomia, que [...] era uma área desconhecida por mim. E o meu conhecimento em educação, me ajudou bastante com o contato com o público de visitantes. (depoimento, mediador 7 - Mast, setembro de 2012)

O curso de licenciatura em física me ajudou na comunicação e expressão de ideias, na didática, com o uso conceitos físicos na explicação de fenômenos naturais e tecnologias na vida cotidiana, nas montagens experimentais e a compreender melhor a relação entre ciência, tecnologia e sociedade. (depoimento, mediador 9 - Mast, setembro de 2012)

Alguns mediadores (3) não reconhecem nenhuma contribuição de sua formação acadêmica prévia ao seu trabalho, por não possibilitar o desenvolvimento de competências especificamente pertinentes ao trabalho de mediação. Desses, dois não tiveram formação em educação, como no depoimento abaixo:

Não (contribuiu) diretamente, porque acredito que a comunicação entre mediador e público nos museus de ciências não deva se restringir à comunicação de conteúdos científicos. A formação necessária a um mediador deve ir muito além de conceitos teóricos de ciências. No meu curso de graduação, discussões sobre a natureza do trabalho científico, dos aspectos históricos e sociológicos da ciência estiveram totalmente ausentes. Outras questões importantes para a mediação (como a comunicação, expressão corporal e linguagem adequada para lidar com o público) nunca fariam parte do meu curso de graduação, que foi em astronomia, pois não havia qualquer disciplina sobre educação, ou sobre educação não formal, na minha grade curricular. (depoimento, mediador 10 - Mast, novembro de 2012)

Os mediadores dos museus em questão destacam a importância da formação acadêmica prévia em educação para o seu desenvolvimento profissional, como 
verificado também por diversos autores (SOARES, 2003; ALENCAR, 2008; OVIGLI, 2009). A formação acadêmica em educação é essencial na formação dos mediadores, para que atuem nesses espaços não formais de educação, pois:

[...] os mediadores de museus recém-chegados à educação não formal tendem, naturalmente, a aplicar os conhecimentos, disciplinares e pedagógicos, trazidos da formação universitária, uma vez que não existe uma formação própria que os preparem para atuar. (SOARES, 2003, p. 84)

De acordo com os sujeitos da presente pesquisa, a sua formação acadêmica Ihes conferiu habilidades interessantes ao seu trabalho como profissionais de educação em museus, mediante, principalmente, os conhecimentos referentes a saberes disciplinares e da formação profissional. Resultados semelhantes encontraram Ovigli e Freitas:

[...] quanto à interface graduação/atuação no museu, as [...] monitoras concordam que os conteúdos específicos, estudados durante a graduação, contribuíram para sua atuação no centro de ciências, sendo para elas fundamental conhecer bem os conceitos científicos presentes na exposição. O desenvolvimento de competências comunicativas, segundo as monitoras, pôde ser desenvolvido parcialmente durante a graduação [...], em especial nas disciplinas pedagógicas. (2009, p. 702)

\section{7- Considerações finais}

A formação de mediadores, assim como a de professores, envolve diversos saberes, como se notou nos casos estudados. Ainda que tenha sido observada ênfase nos saberes disciplinares e nos saberes da formação profissional em cada um dos museus, todos os tipos de saberes propostos por Tardif (2010) têm pertinência para a formação de mediadores, sobretudo os saberes da experiência, valorizados em ambos os casos.

No ECV e no Mast, os profissionais em questão tiveram acesso a uma formação que não se refere apenas a capacitar para o trabalho nesses locais, mas estão relacionados também à formação acadêmica e profissional desses educadores, de maneira mais abrangente, no que se refere à complementação de sua formação pedagógica para atuação em outras atividades, inclusive na escola.

Considera-se que o contato com saberes da formação profissional, específicos da educação em museus, contribui para a formação de futuros professores, pois fornece um embasamento teórico que possibilita que eles utilizem com seus alunos os espaços não formais de educação com maior autonomia, enriquecendo-a. 
Além disso, pondera-se que os saberes da experiência construídos durante a atuação de professores em formação nos museus de ciência, incluindo a aplicação de saberes disciplinares em um novo contexto educacional, possibilita uma diversificação de seu repertório de saberes, o que pode refletir qualitativamente em suas práticas pedagógicas em contextos de educação formal.

Do ponto de vista dos espaços de educação não formal, o estabelecimento de parcerias com instituições de formação de professores é uma questão premente para uma melhor qualificação dos profissionais que atuam na área. Por outro lado, entendese também que esse diálogo pode colaborar para a formação de docentes da educação básica. O educador pode ser compreendido de maneira ampla, e, na sua formação, devem ser valorizadas as possibilidades, especificidades e complementaridades de espaços formais e não formais de educação.

\section{Referências bibliográficas}

ALENCAR, Valeria. O mediador cultural: considerações sobre a formação e profissionalização de educadores de exposições e museus de arte. São Paulo, 2008. Dissertação (Mestrado em Artes) - Universidade Estadual Paulista, Instituto de Artes. São Paulo, 2008.

ALMEIDA, Patrícia; BIAJONE, Jefferson. Saberes docentes e formação inicial de professores: implicações e desafios para as propostas de formação. Educação e Pesquisa, v.33, n.2, p. 281-295,2007.

BORGES, Cecília; TARDIF, Maurice. Dossiê: os saberes docentes e sua formação. Educação e Sociedade, v.22, n.74, p. 11-26, 2001.

CARVALHO, Marcelo. Um estudo sobre a inserção de atividades em educação não formal na disciplina Metodologia e Prática de Ensino de Física na Universidade Estadual de Londrina. Londrina, 2009. Dissertação (Mestrado em Ensino de Ciências e Educação Matemática) - Universidade Estadual de Londrina. Londrina, 2009.

CAZELLI, Sibele; COIMBRA, Carlos Alberto Quadros. Avaliar as ações educativas em museus: como, para quê e por quê? In: ENCONTRO NACIONAL DA REDE DE EDUCADORES EM MUSEUS E CENTROS CULTURAIS DO ESTADO DO RIO DE JANEIRO, 1, 2007, Rio de Janeiro. Anais... Rio de Janeiro: Fundação Casa de Rui Barbosa, 2010. (Coleção FCRB Aconteceu; 10). p. 165-187.

COUTINHO-SILVA, Robson et al. Interação museu de ciências-universidade: contribuições para o ensino não formal de ciências. Ciência e Cultura, v.57, n.4, p. 24-25, 2005. Disponível em:

$<$ http://cienciaecultura.bvs.br/scielo.php?pid=S0009-

67252005000400015\&script=sci_arttext>. Acesso em: 07 abr. 2013. 
GUIMARÃES, Mauro; VASCONCELLOS, Maria das Mercês. Relações entre educação ambiental e educação em ciências na complementaridade dos espaços formais e não formais de educação. Educar, n.27, p. 147-162, 2006.

JACOBUCCI, Daniela; JACOBUCCI, Giuliano; MEGID-NETO, Jorge. Formação continuada de professores em centros e museus de ciências no Brasil. In: REUNIÃO ANUAL DA ASSOCIAÇÃO NACIONAL DE PÓS-GRADUAÇÃO E PESQUISA EM EDUCAÇÃO, 30, 2007, Caxambu. Anais... Caxambu: ANPED, 2007. v.1.

Disponível em:

$<$ http://www.bibliotecadigital.unicamp.br/document/?code=vtls000406918> Acesso em: 09 abr. 2013.

MAHOMED, Carla; FALCÃO, Douglas. Museus de ciências e a formação de professores: estruturando relações. In: ENCONTRO NACIONAL DE PESQUISA EM EDUCAÇÃO EM CIÊNCIAS, 7, 2009, Florianópolis. Anais... Belo Horizonte: ABRAPEC, 2009.

Disponível em: <http://posgrad.fae.ufmg.br/posgrad/viienpec/pdfs/1666.pdf>. Acesso em: 09 abr. 2013.

MARANDINO, Martha (Org.). Educação em museus: a mediação em foco. São Paulo: Grupo de Estudo e Pesquisa em Educação Não Formal e Divulgação da Ciência/ Universidade de São Paulo/Faculdade de Educação, 2008.

MARADINO, Martha et al. Abordagem qualitativa nas pesquisas em educação em museus. ENCONTRO NACIONAL DE PESQUISA EM EDUCAÇÃO EM CIÊNCIAS, VII, 2009. Anais..., Florianópolis, 2009.

MASSARANI, Luisa; MERZAGORA, Matteo; RODARI, Paola (Org.). Diálogos e ciência: mediação em museus e centros de ciências. Rio de Janeiro: Museu da Vida/ Casa de Oswaldo Cruz/ Fiocruz, 2007.

MUSEU DE ASTRONOMIA E CIÊNCIAS AFINS. Plano diretor 2011-2015: planejamento estratégico do MAST. Rio de Janeiro: Ministério da Ciência, da Tecnologia e Inovação, 2010.

Disponível em: <http://www.mast.br/pdf/plano_diretor_2011_2015.pdf> Acesso em: 04 abr. 2013.

OVIGLI, Daniel. Os saberes da mediação humana em centros de ciências: contribuições para a formação inicial de professores. São Carlos, 2009. Dissertação (Mestrado em Educação) - Universidade Federal de São Carlos. São Carlos, 2009.

; FREITAS, Denise. Contribuições de um centro de ciências para a formação inicial do professor. In: SIMPÓSIO NACIONAL DE ENSINO EM CIÊNCIAS E TECNOLOGIA, 1, 2009, Ponta Grossa. Anais... Ponta Grossa: Universidade Tecnológica Federal do Paraná, 2009. p. 693-708.

QUEIROZ, Gloria et al. Construindo saberes da mediação na educação em museus de ciência: o caso dos mediadores do Museu de Astronomia e Ciências Afins. Revista Brasileira de Pesquisa em Educação em Ciências, v.2, n.2, p. 77-88, 2002.

; GOUVÊA, Guaracira; FRANCO, Creso. Formação de professores e museus de ciência. In: GOUVÊA, Guaracira; MARANDINO, Martha; LEAL, Maria Cristina (Org.). Educação e museu: a construção social do caráter educativo dos museus de ciências. Rio de Janeiro: Access/Faperj, 2003. p. 207-220. 
RIBEIRO, Maria das Graças; FRUCCHI, Graciela. Mediação - a linguagem humana dos museus. In: MASSARANI, Luisa; MERZAGORA, Matteo; RODARI, Paola (Orgs.). Diálogos e ciência: mediação em museus e centros de ciências. Rio de Janeiro: Museu da Vida/ Casa de Oswaldo Cruz/ Fiocruz, 2007. p. 67-74.

ROCHA, Marcele Augusta. Análise da mediação de um museu de ciências. Rio de Janeiro, 2011. Trabalho de conclusão de curso (especialização em Ensino de Ciências) - Instituto Federal de Educação Ciência e Tecnologia do Rio de Janeiro, Rio de Janeiro, 2011.

SOARES, Jorge Mendes. Saberes da mediação humana em museus de ciência e tecnologia. Niterói, 2003. Dissertação (Mestrado em Educação) - Universidade Federal Fluminense. Niterói, 2003.

TARDIF, Maurice. Saberes docentes e formação profissional. 10ªed. Petrópolis: Vozes, 2010. 